\title{
Poor Hand Hygiene Procedure Compliance among Polish Medical Students and Physicians-The Result of an Ineffective Education Basis or the Impact of Organizational Culture?
}

\author{
Marta Wałaszek $^{1}$, Małgorzata Kołpa ${ }^{1}$, Zdzisław Wolak $^{1}$, Anna Różańska ${ }^{2}$ and \\ Jadwiga Wójkowska-Mach ${ }^{2, *}$ \\ 1 State Higher Vocational School in Tarnów, 33-100 Tarnów, Poland; mz.walaszek@gmail.com (M.W.); \\ malgorzatakolpa@interia.pl (M.K.); zdzich_w@interia.pl (Z.W.) \\ 2 Chair of Microbiology, Faculty of Medicine, Jagiellonian University Medical College, ul. Czysta 18, \\ 31-121 Kraków, Poland; rozanska@ifb.pl \\ * Correspondence: mbmach@cyf-kr.edu.pl; Tel.: +48-126-336-033, Fax: +48-124-233-924
}

Received: 13 July 2017; Accepted: 4 September 2017; Published: 7 September 2017

\begin{abstract}
Objective: The objective of the study was to examine the knowledge of Polish physicians and medical students about the role of hand hygiene (HH) in healthcare-associated infection (HAI) prevention. Study design: A survey was conducted using an author-prepared questionnaire, which was filled out on the first day of hospital work (or internship) by newly admitted physicians who had worked in other hospitals and students of different medical schools in Poland. Methods: 100 respondents participated in the study: 28 students, 18 medical interns and 54 physicians. Results: As many as 3/4 of physicians and students did not use the $\mathrm{HH}$ techniques correctly. The respondents declared that they perform $\mathrm{HH}$ in the following situations: $74.4 \%$ of respondents before an aseptic task; $60.8 \%$ before patient contact; $57.0 \%$ after patient contact; $11.5 \%$ after body fluid exposure risk, and only two respondents $(1.1 \%$ ) after contact with patient surroundings. $64 \%$ of respondents declared that their supervisor checked their knowledge of the $\mathrm{HH}$ technique when they were touching patients, but their supervisors checked the five instances for $\mathrm{HH}$ only in the case of 27 respondents $(27 \%)$. Students experienced any control of $\mathrm{HH}$ in the workplace less often. Interns and physicians mentioned that the most important preventive action in HAI is $\mathrm{HH}$, but for students it is the use of gloves. Conclusions: The level of knowledge and skills of physicians and students in the field of $\mathrm{HH}$ is insufficient. Deficiencies in skills and knowledge of $\mathrm{HH}$ were identified as early as at the level of the first internship.
\end{abstract}

Keywords: hand hygiene; healthcare-associated infections; medical students; physicians

\section{Introduction}

The first recommendations for hand hygiene $(\mathrm{HH})$ in medical settings were initially based on the recommendation to wash hands with soap and water and rinsing hands with an antiseptic agent was recommended only if water was unavailable. However, the study by Rotter [1] on hand disinfection efficiency revolutionized the approach to $\mathrm{HH}$ and had been recommended for hand disinfection for many years in place of washing hands, also in Poland [2]. HH should be applied at five moments as indicated by the WHO: (1) before patient contact; (2) before an aseptic task; (3) after body fluid exposure risk; (4) after patient contact; (5) after contact with patient surroundings [2,3]. It was confirmed by Allagranzi et al. [4] that the WHO campaign in the field of $\mathrm{HH}$ is effective in numerous studies that were subjected to meta-analysis. 
However, medical personnel face many difficulties in the implementation of $\mathrm{HH}$ rules. These difficulties have been described in various studies from around the world. HH is not always conducted in accordance with the principle of the 5 Moments for $\mathrm{HH}$, and compliance with these rules is estimated at around $40 \%$ of needs [5]. Particularly low compliance rates were obtained in studies conducted among interns [6,7]. The results of studies conducted by different Polish authors also show low compliance rates with HH recommendations [8-12]. It is difficult to clearly state what causes the problems as regards compliance with HH rules in Poland. Some authors point to the flawed organization of the infection control system, which can result from the short post-transformation history [13], and others indicate the national culture in the hospital-acquired infection (HAI) surveillance system, which is specific to a given country and the planning and operation of which may have a positive impact on HAI prevention practices, including HH [14-16]. In the literature it is more often noticed that the success of $\mathrm{HH}$ campaigns is affected by the contextual factors of the organization, such as the involvement of the hospital administration and the good example presented by managers and senior managers $[17,18]$. However, in countries where local cultural factors are ignored such campaigns may not produce the expected results [19-23].

The main objective of this 2016 study was to examine the knowledge and skills of medical students and physicians in the field of $\mathrm{HH}$ in the context of HAI prevention, using a standardized questionnaire survey, and to additionally identify the possible cause of the current condition via a qualitative interview survey. Moreover, an observational study of $\mathrm{HH}$ practices was performed in order to check the data received from the questionnaire and the interviews.

\section{Methods}

Three research methods were employed in the study: a quantitative method, i.e., the use of a questionnaire designed by the authors, a qualitative method involving interviews (based on the structured questionnaire), and observation of the Ayliffe handwashing technique. The questionnaire surveys and interviews were anonymous. The questions used in the questionnaire survey and in structured interviews are presented in Table 1. All groups (students, interns and physicians) took part in the questionnaire survey-100 respondents, comprising 65 women $(56.9 \%)$ and 35 men $(48.6 \%)$. In this group, there were 28 medical students $(28 \%), 18$ intern physicians $(18 \%)$ and 54 physicians $(54 \%)$. The structured interviews were conducted only with students and interns since physicians refused to participate in this part of the study. Interviews were recorded and transcripts were later prepared by the interviewer. In addition, between 2010 and 2017, the Infection Prevention and Control Team reviewed the Ayliffe $\mathrm{HH}$ technique among physicians and students hired.

The study was conducted in 2016 among physicians and medical students undertaking internships in a 500-bed specialist multiprofile hospital located in Tarnow (south east Poland). Three different groups of respondents took part in this study: medical students, intern physicians, and newly hired physicians at the hospital.

Medical students participating in the study were students who had completed the first year of studies and were selected for a holiday medical internship in the hospital where the study was conducted. Intern physicians (the second group) are physicians who graduated from a 5-year medical school and passed the National Medical Exam and work in a hospital of their choice for 1 year before their independent medical practice. The third group consisted of physicians who were newly admitted to the hospital in which this study was conducted (in this group there were both residents, i.e., physicians during specialization and fully qualified ones).

In the case of students and intern physicians, the assumption was made that they had studied at or graduated from medical schools located in various Polish cities. Both the students and physicians chose the study hospital for their internship because it was close to the place of their permanent residence. This allowed the authors to obtain a diverse group of people who had studied at different medical schools in Poland. 
Table 1. Questions used in the questionnaire survey and in structured interviews.

\begin{tabular}{c}
\hline Questionnaire Survey-Questions about Respondents' Knowledge of Selected Aspects of HH \\
what are the main measures aimed at preventing HAIs? \\
when should they be performed? ('5 Moments for HH') \\
\hline whether anyone (and if yes-who) in the hospital inspected their Ayliffe HH technique \\
\hline whether anyone (and if yes-who) in the hospital inspected the 5 Moments for Hand Hygiene \\
\hline what situations encountered in everyday work influence compliance with HH recommendations? \\
what would encourage medical personnel to obey HH rules better? \\
Structured Interviews-Questions \\
\hline can you list the '5 Moments for HH'? \\
\hline how would you feel if a patient made a remark about omitting hand hygiene? \\
\hline what is the level of compliance with HH recommendations among healthcare workers? \\
were HH recommendations included in your studies? \\
was it only a theoretical or also a practical approach? \\
what could help us build a positive attitude towards HH? \\
\hline have you experienced any severe situations concerning disobeying the HH rules? \\
would you report anybody who disobeys the HH rules?
\end{tabular}

In the questionnaire, responses to the questions concerning HAI prevention were rated by assigning the rank to individual activities from 1 (invalid) to 7 (very important) according to the Likert scale. As for the question concerning difficulties in compliance with the $\mathrm{HH}$ procedure, points were assigned for each action according to the Likert scale ranging from 1 (no obstacle) to 5 (a very big obstacle).

The group of 127 physicians was covered by the observational study (no medical students were included). Among them there were 72 physicians, including the group of 54 taking part in the questionnaire survey, and 55 intern physicians, including the group of 18 taking part in the questionnaire. The hospital, in which this study was conducted, refers every newly-hired employee to the team in order to verify their ability to perform the Ayliffe $\mathrm{HH}$ technique.

For statistical analysis, all factors that may influence the proper use of $\mathrm{HH}$ by physicians, such as sex, age, education, seniority, and place of work were considered as independent variables. Statistical analysis of the collected material was carried out with the use of the IBM Statistical Package for the Social Sciences (IBM SPSS v.4, Armonk, NY, USA) and Microsoft Office Excel (2003, Redmond, Washington, DC, USA). The description of data on the whole population surveyed was compiled with the use of basic statistical parameters, such as mean and standard deviations, confidence intervals, minimum and maximum. In order to compare the incidence of qualitative variants in several populations, the chi-square test of independence and measurement error or uncertainty indicators were used.

\section{Results}

\subsection{Structured Questionnaire}

Activities related to $\mathrm{HH}$ were pointed out by the respondents as the most important in the area of HAI prevention - in this case the highest estimated mean value was 5.9 (median, Me 7). Respondents equally highly evaluated the use of disposable gloves (mean 5.4, Me 6) and adherence to aseptic technique (mean 5.3, Me 6). Substantial differences in the perception of HAI prevention were observed depending on the occupational group. The most important activity indicated by interns (I) and physicians (P) was $\mathrm{HH}$ (on average 6.2 and 6.0), and according to medical students (MS) it was the use of gloves (average 6.6). Detailed results are presented in Table 2. 
Table 2. Main measures to prevent healthcare associated infections according to professional groups.

\begin{tabular}{ccccccc}
\hline $\begin{array}{c}\text { Activities Related to } \\
\text { HAI Prevention }\end{array}$ & Professional Groups & $\boldsymbol{N}$ & $\begin{array}{c}\text { Average Values } \\
\text { in Groups }\end{array}$ & Median & Standard Deviation & 95\% CI \\
\hline \multirow{3}{*}{ Hand-hygiene } & Medical student & 28 & 5.6 & 6.0 & 2.71 & $4.649,6.494$ \\
& Medical intern & 18 & 6.2 & 7.0 & 2.71 & $4.873,7.571$ \\
& Physician & 54 & 6.0 & 7.0 & 2.78 & $5.241,6.759$ \\
\hline \multirow{3}{*}{ Use of disposable gloves } & Medical student & 28 & 6.6 & 7.0 & 1.52 & $6.016,7.198$ \\
& Medical intern & 18 & 5.0 & 5.5 & 2.57 & $3.724,6.276$ \\
& Physician & 54 & 4.9 & 5.0 & 2.41 & $4.229,5.548$ \\
\hline \multirow{2}{*}{ Adherence to } & Medical student & 28 & 5.2 & 5.0 & 1.97 & $4.451,5.978$ \\
aseptic technique & Medical intern & 18 & 5.5 & 6.0 & 2.50 & $4.255,6.745$ \\
& Physician & 54 & 5.3 & 6.0 & 2.63 & $4.616,6.051$ \\
\hline
\end{tabular}

However, the knowledge of $\mathrm{HH}$ demonstrated by the respondents in their answers to the open question appeared to be unsatisfactory. Only 79 respondents answered this question. From the situations (moments) in which (according to the WHO) HH should be performed, only 59 respondents $(74.7 \%)$ indicated the moments before clean/aseptic tasks; 48 (60.8\%) before patient contact; $45(57.0 \%)$ after patient contact; $20(25.3 \%)$ after body fluid exposure risk, and only $2(2.5 \%)$ after contact with patient surroundings (Table 3). The interns gave most correct answers: $80 \%$ pointed to three situations in which $\mathrm{HH}$ was required: before patient contact; before clean/aseptic tasks; and after patient contact. The group of physicians most frequently mentioned HH before clean/aseptic tasks (85.7\%) (Table 3).

Table 3. Answers to the multiple choice question: List situations in which a healthcare worker should perform hand hygiene according to the 5 Moments for Hand Hygiene with the division into professional groups. Number of respondents: 79, no answer: 21.

\begin{tabular}{|c|c|c|c|c|c|}
\hline \multicolumn{2}{|c|}{5 Moments for Hand Hygiene } & \multirow{3}{*}{$\begin{array}{c}\text { Medical Student } \\
13(59.1) \\
16.5 \%\end{array}$} & \multirow{3}{*}{$\begin{array}{c}\text { Medical Intern } \\
12(80.0) \\
15.2 \%\end{array}$} & \multirow{3}{*}{$\begin{array}{c}\text { Physician } \\
23(54.8) \\
29.1 \%\end{array}$} & \multirow{3}{*}{$\begin{array}{c}\text { Total } \\
48 \\
60.8 \%\end{array}$} \\
\hline Before patient contact & In a professional group $N(\%)$ & & & & \\
\hline Before patient contact & $\%$ of total & & & & \\
\hline \multirow{2}{*}{$\begin{array}{l}\text { Before clean/ } \\
\text { aseptic tasks }\end{array}$} & In a professional group $N(\%)$ & $11(50.0)$ & $12(80.0)$ & $36(85.7)$ & 59 \\
\hline & $\%$ of total & $13.9 \%$ & $15.2 \%$ & $45.6 \%$ & $74.7 \%$ \\
\hline \multirow{2}{*}{$\begin{array}{l}\text { After body fluid } \\
\text { exposure risk }\end{array}$} & In a professional group $N(\%)$ & $9(40.9)$ & $2(13.3)$ & $9(21.4)$ & 20 \\
\hline & $\%$ of total & $11.4 \%$ & $2.5 \%$ & $11.4 \%$ & $25.3 \%$ \\
\hline \multirow{2}{*}{ After patient contact } & In a professional group $N(\%)$ & $13(59.1)$ & $12(80.0)$ & $20(47.6)$ & 45 \\
\hline & $\%$ of total & $16.5 \%$ & $15.2 \%$ & $25.3 \%$ & $57.0 \%$ \\
\hline \multirow{2}{*}{$\begin{array}{l}\text { After contact with } \\
\text { patient surroundings }\end{array}$} & In a professional group $N(\%)$ & $0(0.0)$ & $1(6.7)$ & $1(2.4)$ & 2 \\
\hline & $\%$ of total & $0.0 \%$ & $1.3 \%$ & $1.3 \%$ & $2.5 \%$ \\
\hline \multirow{2}{*}{ Total } & In a professional group $N(\%)$ & $22(27.8)$ & $15(19.0)$ & $42(53.2)$ & $79(100.0)$ \\
\hline & $\%$ of total & $27.8 \%$ & $19.0 \%$ & $53.2 \%$ & $100.0 \%$ \\
\hline
\end{tabular}

As regards the question, "Has your Ayliffe technique ever been checked?", only 64 respondents (64\%) confirmed that such an inspection ever took place. An even worse result was obtained when the question about the 5 Moments for $\mathrm{HH}$ was asked: "Has your ability to recognize the 5 Moments for HH ever been checked?" Only 27 respondents (28\%) answered affirmatively.

In order to further investigate the abovementioned issue, the following question was asked: "Who checked your Ayliffe hand washing technique?" We received answers from only 64 respondents. The next question was as follows: "Who reviewed the situations in which you apply the 5 Moments for $\mathrm{HH}$ ?" Only 26 respondents answered. In most cases the control of $\mathrm{HH}$ was conducted by the nurse in charge. The nurses in charge conducted the control of $\mathrm{HH}$ in 25 cases (39.1\%) out of the 64 respondents. Similarly, the nurses in charge controlled the 5 Moments for HH in 12 cases (46.2\%) of respondents out of 28 respondents who reported that they experienced any such control. The study shows the low participation of teachers (internship supervisors) in carrying out such inspections. In addition, the Head Physicians (department managers) showed little action in the field of HH control. The most active group comprised nurses in charge, especially in relation to the group of students whom they supervised during internship after the first year of medical studies (Table 4). The interviews 
highlighted the existence of barriers between different medical personnel groups concerning the necessity to remind them about performing $\mathrm{HH}$ in the required situations.

Table 4. Answer the question: Who checked your Ayliffe hand washing technique and the 5 Moments for Hand Hygiene $[2,3]$ ?

\begin{tabular}{|c|c|c|c|c|c|c|c|c|}
\hline \multirow{2}{*}{ Professional Groups } & \multicolumn{4}{|c|}{$\begin{array}{l}\text { Who Reviewed the Ayliffe Hand Washing Technique? } \\
\qquad \text { (\%) }\end{array}$} & \multicolumn{4}{|c|}{$\begin{array}{l}\text { Who Checked the ' } 5 \text { Moments for Hand Hygiene'? } \\
\qquad N(\%)\end{array}$} \\
\hline & $\begin{array}{c}\text { Head } \\
\text { Physician }\end{array}$ & $\begin{array}{l}\text { Nurse in } \\
\text { Charge }\end{array}$ & $\begin{array}{l}\text { Teacher/Internship } \\
\text { Supervisor }\end{array}$ & Total & $\begin{array}{c}\text { Head } \\
\text { Physician }\end{array}$ & $\begin{array}{l}\text { Nurse in } \\
\text { Charge }\end{array}$ & $\begin{array}{l}\text { Teacher/Internship } \\
\text { Supervisor }\end{array}$ & Total \\
\hline Medical student & $2(16.7)$ & $9(75.0)$ & $1(8.3)$ & $12(100)$ & $0(0.0)$ & $5(100.0)$ & $0(0.0)$ & $5(100)$ \\
\hline Medical intern & $0(0.0)$ & $3(30.0)$ & $7(70.0)$ & $10(100)$ & $0(0.0)$ & $2(50.0)$ & $2(50.0)$ & $4(100)$ \\
\hline Physician & $17(40.5)$ & $13(32.0)$ & $12(28.6)$ & $42(100)$ & $6(35.35)$ & $5(29.4)$ & $6(35.3)$ & $17(100)$ \\
\hline \multirow[t]{2}{*}{ Total } & $19(29.7)$ & $25(39.1)$ & $20(31.1)$ & $64(100)$ & $6(21.1)$ & $12(46.2)$ & $8(30.85)$ & $26(100)$ \\
\hline & \multicolumn{4}{|c|}{$\begin{array}{c}\text { Lack of answer } n=36 \\
\text { Chi-square of Pearson } p<0.01\end{array}$} & \multicolumn{4}{|c|}{$\begin{array}{c}\text { Lack of answer } n=74 \\
\text { Chi-square of Pearson } p<0.05\end{array}$} \\
\hline
\end{tabular}

Respondents were asked the following question: What situations encountered in everyday work influence compliance with $\mathrm{HH}$ recommendations? In most cases, respondents pointed to difficulties in accessing soap, towels and disinfectants, and the inadequate quality of disinfectants, which caused irritation. Respondents also showed a skeptical approach to $\mathrm{HH}$, forgetting about $\mathrm{HH}$, and the belief that the use of gloves is sufficient (Table 5).

Table 5. Answers to the question: What situations encountered in everyday work affect compliance with $\mathrm{HH}$ recommendations? SD—standard deviation; 95\% CI.

\begin{tabular}{ccccc}
\hline Situation or Opinion That Impedes Hand Hygiene & Number & Mean & SD & $\mathbf{9 5 \%}$ CI \\
\hline Lack of soap and towels & 54 & 4.5 & 0.79 & $4.265,4.698$ \\
Insufficient amount of disinfectants & 54 & 4.3 & 0.69 & $4.125,4.505$ \\
Disinfectants causing irritation & 54 & 3.7 & 0.82 & $3.461,3.909$ \\
Skeptical attitude to hand hygiene & 54 & 3.6 & 1.27 & $3.247,3.938$ \\
Forgetting about hand hygiene & 54 & 3.6 & 1.09 & $3.276,3.872$ \\
The use of gloves is sufficient & 54 & 3.5 & 1.11 & $3.803,3.197$ \\
Disagreement with hand hygiene recommendations & 54 & 3.3 & 1.28 & $2.928,3.627$ \\
Overload of activities & 54 & 3.2 & 0.95 & $2.964,3.480$ \\
Lack of specific hand hygiene rules & 54 & 3.2 & 1.12 & $2.897,3.510$ \\
Lack of pattern of conduct among colleagues and supervisors & 54 & 3.1 & 1.12 & $2.749,3.362$ \\
Lack of a reward and punishment system & 54 & 2.2 & 1.01 & $1.926,2.481$ \\
\hline
\end{tabular}

Respondents were asked an open question: What would encourage medical personnel to obey $\mathrm{HH}$ rules better? The highest proportion of answers pointed to the need for a greater number of courses (35 respondents, $24.8 \%$ ). Other answers indicated access to good quality disinfectants ( 28 respondents, $19.9 \%$ ), a better supply of $\mathrm{HH}$ products ( 21 respondents, $14.5 \%$ ), and others listed in Table 6.

Table 6. Answers to the multiple choice question: What would encourage medical personnel to obey $\mathrm{HH}$ rules better? Number of respondents: 79, no answer: 21 .

\begin{tabular}{ccc}
\hline \multirow{2}{*}{ Suggestions for Improving Hand Hygiene } & \multicolumn{2}{c}{ Answers } \\
\cline { 2 - 3 } & $\boldsymbol{N} \mathbf{( \% )}$ & Percent of Observations \\
\hline More training & $35(24.8)$ & $42.2 \%$ \\
Hand hygiene products of good quality & $28(19.9)$ & $33.7 \%$ \\
Better supply of hand hygiene products & $21(14.9)$ & $25.3 \%$ \\
A system of rewards and punishments & $15(10.6)$ & $18.1 \%$ \\
More frequent inspections & $14(9.9)$ & $16.9 \%$ \\
Good models & $10(7.1)$ & $12.0 \%$ \\
Increasing the number of personnel & $9(6.4)$ & $10.8 \%$ \\
Personnel's positive attitude & $5(3.5)$ & $6.0 \%$ \\
Verbal reprimands & $4(2.8)$ & $4.8 \%$ \\
Total & $141(100.0)$ & $169.9 \%$ \\
\hline
\end{tabular}




\subsection{Structured Interviews}

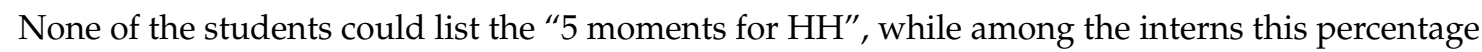
was lower and amounted to $82 \%$. Medical students favored hand washing and use of gloves $(83 \%)$ as essential $\mathrm{HH}$ practices. Interns leaned towards hand disinfection $(47 \%)$, hand washing $(24 \%)$ or washing and disinfection (29\%). Both medical students and interns stated that patients had never asked them to apply $\mathrm{HH}(56 \%)$; however, if it had happened, they would have been embarrassed. $9 \%$ of respondents would have felt obliged to comply and almost half would have been surprised or embarrassed.

Only $29 \%$ of medical students confirmed in their interviews that the educational program of their studies covered elements involving hand hygiene. As for interns, this proportion was higher and amounted to $65 \%$. Medical students most often mentioned theoretical hand hygiene classes $(21 \%)$. In the course of their education, theory was rarely combined with practice $(7 \%)$. The interns more often pointed out theory $(41 \%)$, practice $(35 \%)$ and combining theory with practice $(23 \%)$.

As regards hand hygiene practices, the interns complained most frequently about low availability of hand hygiene preparations (41\%), requested more training (35\%) and substances of better quality (24\%). Medical students needed HH trainings the most (61\%).The interns often observed situations when medical staff did not comply with $\mathrm{HH}$ guidelines (77\%). Medical students witnessed such events much less frequently (29\%). Neither interns $(94 \%)$ nor medical students $(61 \%)$ were inclined to remind others about the necessity to conduct hand hygiene in the required situations.

\subsection{Observational Study}

In addition to the results of the diagnostic survey described above, the inspection of the Ayliffe $\mathrm{HH}$ technique was conducted in the hospital from 2010 to 2017 among 127 physicians, including a group of 54 newly-hired physicians taking part in the questionnaire survey. The review was conducted on the day a physician was collecting the documents required to start work. One of the required documents is the so-called "new employee orientation checklist". It is required that the infection control (IC) team confirms on this checklist that an applicant has mastered skills in the field of HH. In 2010-2017, 127 physicians were checked on the correct use of the Ayliffe $\mathrm{HH}$ technique. An unfavorable situation in this area was recorded and it remained unchanged for many years as the distribution in the examined group over the years has not shown significant statistical differences between the HH skills in individual years $(p=0.327)$. The number of people who correctly performed $\mathrm{HH}$ are as follows: eight interns out of $55(14.5 \%)$ and 24 out of 72 physicians (33.3\%). The differences between the professional groups of physicians were statistically significant $(p<0.05)$ (Table 7$)$.

Table 7. Summary of observations on compliance with the Ayliffe hand washing technique made between 2010 and 2017 with division into professional groups.

\begin{tabular}{ccccc}
\hline Year & Non-Compliant $N$ (\%) & Compliant $N$ (\%) & Total $N(\%)$ & $p^{*}$ \\
\hline 2010 & $8(8.4)$ & $4(12.5)$ & $12(9.4)$ & \\
2011 & $11(11.6)$ & $3(9.4)$ & $14(11.0)$ & \\
2012 & $3(3.2)$ & $1(3.1)$ & $4(3.1)$ & \\
2013 & $13(13.7)$ & $4(12.5)$ & $17(13.4)$ & 0.327 \\
2014 & $15(15.8)$ & $6(18.8)$ & $21(16.5)$ & \\
2015 & $29(30.5)$ & $4(12.5)$ & $33(26.0)$ & \\
2016 & $11(11.6)$ & $9(28.1)$ & $20(15.7)$ & \\
2017 & $5(5.3)$ & $1(3.1)$ & $127(100.0)$ & \\
Total & $95(100.0)$ & $32(100.0)$ & $72(100.0)$ \\
\hline \multicolumn{5}{c}{}
\end{tabular}

${ }^{*}$ From Chi-suqare of Pearson test. 


\section{Discussion}

The use of triangulation, involving three methods to collect data (survey, interview, observation), was applied in this study to deepen research in the field of $\mathrm{HH}$ and, in particular, to broaden the knowledge of the context of the phenomenon studied. Both quantitative (survey, observation) and qualitative (interviews) studies responded to the questions asked by the authors of this paper regarding poor compliance with $\mathrm{HH}$ rules by physicians. Although the long history of HAI surveillance in the world indicates $\mathrm{HH}$ as a primary activity in HAI prevention, many scientific reports indicate deficiencies in knowledge in this area $[2,6,7,18,24]$. Also, on the basis of studies conducted in Poland, it can be concluded that compliance with $\mathrm{HH}$ rules by medical personnel is far from what should be expected [8-12]. The lack of basic knowledge about HH is already apparent in the case of first year students who should have basic knowledge in the field of $\mathrm{HH}$ before their first patient contact. In this study, students incorrectly indicated the importance of using protective gloves as the most important action in HAI prevention. These results may indicate that the HH rules are not promoted strongly enough in medical schools. It is hard to say whether students' opinions were guided by patient welfare, or whether they were worried about their own health before patient contact; hence, the lack of experience or knowledge in this area means that they chose the simplest solution. Similar results were obtained in another study on the effectiveness of the implementation of $\mathrm{HH}$ programmes [25].

In the study conducted, only a few supervisors controlled the technical skills and frequency of $\mathrm{HH}$ of their subordinate personnel. This situation may mean that a low rank (value) is assigned to $\mathrm{HH}$ as the basic skill required in patient contact. It is true that numerous studies demonstrated the effectiveness of audits in this area [18,25-28].

In the study carried out, it was important for the authors to receive an answer to the following question: Who inspected the Ayliffe technique and the 5 Moments for $\mathrm{HH}$ ? The objective behind this question was to gather information from respondents on the extent to which their knowledge and skills in the field of $\mathrm{HH}$ were strengthened by their supervisors carrying out checks. In most cases, this control was conducted by nurses in charge, and the inspection was less often performed by supervisors and Head Physicians.

Interns emphasized the fact that they acquired HH skills gradually during internship in different hospitals. They also emphasized the role of nurses in acquiring practical skills in the field of hand hygiene. Numerous studies underline the importance of organizational structure in the effective implementation of $\mathrm{HH}$ programmes [17]. Positive leadership at the departmental level appears to be a prerequisite for medical personnel's compliance with HH rules. Supervisors and senior physicians should be aware of their role and demonstrate $\mathrm{HH}$ skills as role models for novice medical professionals [20,29]. In this study, interviews with physicians and students demonstrated the existence of barriers between professional medical groups as regards the need to remind them to perform $\mathrm{HH}$ in the required situations. In medical students' statements, one can notice a reference to the extensive experience of medical personnel and respect for their knowledge, but also socialization taking place in medical schools, which prevents questioning even negative behaviors. Students tend not to speak up in situations when it is necessary to point out that someone is not following HH rules. Undoubtedly, this situation is related to the national culture and the consequent trend towards building hierarchical structures based on a large power distance $[15,19,30]$.

This study revealed the great ignorance of physicians and students with regard to the 5 Moments for $\mathrm{HH}$. During interviews some physicians complained about the lack of $\mathrm{HH}$ procedures at their workplace and students talked about negative situations which they had observed during their internship involving senior physicians and supervisors and the lack of $\mathrm{HH}$ classes in the course of their studies. Numerous studies show that the level of $\mathrm{HH}$ among students and physicians is unsatisfactory. It also concerns other countries [6-9,14].

The physicians and students who took part in the study indicated difficulties in conducting $\mathrm{HH}$, but it should be strongly emphasized that the results of these tests do not refer specifically to the hospital where the study was conducted, but rather to the general problems in different Polish 
hospitals, where the studied group of physicians and students worked. This situation is very disturbing and may suggest that hospital managers implement austerity policies in the field of HH. Among the activities which, according to respondents, would encourage medical personnel to comply with the $\mathrm{HH}$ rules were better education, better access to high quality disinfectants, and better supply of HH products. These results are in part consistent with those of Borg et al. [31] De Bono et al. [15] focus on $\mathrm{HH}$ practices that are the central element of the culture. Culture in this view is defined as the "collective programming of mind", and is characterized by high stability [19]. This means that an attempt to change the practices may be treated by individuals or groups as a threat that may question the foundations of $\mathrm{HH}$ in order to maintain actions and status within the structure of authority. It should be emphasized that the strong resistance to change in Poland is caused by the high level of risk experienced by medical personnel when facing new, unknown and uncertain situations [19]. Resistance to change among Head Physicians and senior managers is the result of uncertainty as to the relevance of new practices which delays and increases the effort to implement evidence-based changes [15].

\section{Conclusions}

(1) The level of knowledge and skills of physicians and medical students in the field of $\mathrm{HH}$ is insufficient and needs to be supplemented with pre/diploma training, and should also be part of postgraduate training.

(2) The participation of managers of hospital departments and teachers in supervising $\mathrm{HH}$ of new physicians and students is inadequate, which may be one of the reasons behind the poor situation in this field.

(3) Physicians and students report that Polish educational programmes for higher medical schools do not contain sufficient training in hand hygiene.

(4) Further studies on the cultural determinants of compliance with HH rules in the medical field are needed to enable their effective implementation.

Acknowledgments: Ethical approval: this is a completed retrospective study and the paper does not report on primary research. The data collected were not set up as a study or research project, but as part of an infection control programme: As part of routine assessment of knowledge and skills in hand hygiene practices of permanent (full-time, physicians) or temporary (medical students) employees in the hospital. This was done internally as part of an audit/evaluation, so as to improve the quality of care. It is done for each newly hired person. The paper does not report on the use of experimental or new protocols. Funding Source: This research did not receive any specific grant from funding agencies in the public, commercial, or not-for-profit sectors. Financial Disclosure: The authors have no financial relationships relevant to this article to disclose.

Author Contributions: Marta Wałaszek conceptualized and designed the study, analyzed and interpreted the data, drafted the manuscript; Małgorzata Kołpa collected data, carried out the initial analyses and statistical analysis; Zdzisław Wolak collected data, carried out the initial analyses; Anna Różańska interpreted data, drafted the manuscript; Jadwiga Wójkowska-Mach analyzed data and gave final approval of the version to be published, the corresponding author.

Conflicts of Interest: The authors declare no conflict of interest.

\section{References}

1. Rotter, M. Vergleich der Wirkung von Wasser, einigen Detergentien und Äthylalkohol auf die transiente Flora der Hände. Zbl. Bakt. Hyg. I Abt. Orig. B 1975, 160, 163-172. (In German)

2. World Health Organization. WHO Guidelines on Hand Hygiene in Health Care. First Part. Global Patient Safety Challenge. Clean Care is Safer Care; WHO Press: Geneva, Switzerland, 2009. Available online: http:/ /apps.who.int/iris/bitstream/10665/44102/1/9789241597906_eng.pdf (accessed on 30 June 2017).

3. Sax, H.; Allegranzi, B.; Uckay Larson, E.; Boyce, J.; Pittet, D. My five moments for hand hygiene: A user-centred design approach to understand, train, monitor and report hand hygiene. J. Hosp. Infect. 2007, 67, 9-12. [CrossRef] [PubMed] 
4. Allegranzi, B.; Gayet-Ageron, A.; Damani, N.; Bengaly, L.; McLaws, M.L.; Moro, M.L.; Memish, Z.; Urroz, O.; Richet, H.; Storr, J.; et al. Global implementation of WHO's multimodal strategy for improvement of hand hygiene: A quasi-experimental study. Lancet. Infect. Dis. 2013, 13, 843-851. [CrossRef]

5. Pittet, D. Improving adherence to hand hygiene practice: A multidisciplinary approach. Emerg. Infect. Dis. 2001, 7, 234-240. [CrossRef] [PubMed]

6. Block, L.; Habicht, R.; Oluysdi, F.O.; Wu, A.W.; Nissen, T.; Silva, K.N.; Oliver, N.; Feldman, L. Variability in hand hygiene practices among internal medicine interns. Am. J. Infect. Control 2013, 41, 1107-1108. [CrossRef] [PubMed]

7. Polacco, M.A.; Shinkunas, L.; Perencevich, E.N.; Kaldjian, L.C.; Reisinger, H.S. See one, do one, teach one: Hand hygiene attitudes among medical students, interns, and faculty. Am. J. Infect. Control 2015, 43, 159-161. [CrossRef] [PubMed]

8. Kawalec, A.; Pawlas, K. Compliance with hygiene procedures among medical faculty students. Med. Pr. 2014, 65, 593-599. [CrossRef] [PubMed]

9. Różańska, A.; Wójkowska-Mach, J.; Bulanda, M. Work experience and seniority in health care vs. medical students' knowledge of selected hand hygiene procedures. Med. Pr. 2016, 67, 623-633. [CrossRef] [PubMed]

10. Garus-Pakowska, A.; Sobala, W.; Szatko, F. Observance of hand washing procedures performed by the medical personnel before patient contact. Part I. Int. J. Occup. Med. Environ. Health 2013, 26, 113-121. [CrossRef] [PubMed]

11. Garus-Pakowska, A.; Sobala, W.; Szatko, F. Observance of hand washing procedures performed by the medical personnel after the patient contact. Part II. Int. J. Occup. Med. Environ. Health 2013, 26, 257-264. [CrossRef] [PubMed]

12. Kołpa, M.; Grochowska, A.; Gniadek, A.; Jurkiewicz, B. Level of knowledge among medical personnel about infections transferred through direct contact—Results of questionnaire survey. Prz. Epidemiol. 2015, 69, 503-506.

13. Ider, B.E.; Adams, J.; Morton, A.; Whithy, M.; Clements, A. Infection control systems in transition: The challenges for post-Soviet Bloc countries. J. Hosp. Infect. 2012, 80, 277-287. [CrossRef] [PubMed]

14. Stone, P.W.; Pogorzelska, M.; Kunches, L.; Hirschhorn, L.R. Hospital staffing and health care-associated infections: A systematic review of the literature. Clin. Infect. Dis. 2008, 47, 937-944. [CrossRef] [PubMed]

15. De Bono, S.; Heling, G.; Borg, M.A. Organizational culture and its implications for infection prevention and control in healthcare institutions. J. Hosp. Infect. 2014, 86, 1-6. [CrossRef] [PubMed]

16. Organization for Economic Cooperation and Development. Doctors (Overall Number), I Health at a Glance: OECD Indicators; OECD Publishing: Paris, France, 2015.

17. Smiddy, M.P.; O'Connell, R.; Creedon, S.A. Systematic qualitative literature review of health care workers' compliance with hand hygiene guidelines. Am. J. Infect. Control 2015, 43, 269-274. [CrossRef] [PubMed]

18. Gould, D.J.; Hewitt-Taylor, J.; Drey, N.S.; Gammon, J.; Chudleigh, J.; Weinberg, J.R. The clean your hands campaign: Critiquing policy and evidence base. J. Hosp. Infect. 2007, 65, 95-101. [CrossRef] [PubMed]

19. Hoftede, G.; Hofstede, G.J.; Minkov, M. Kultury Organizacyjne; McGraw-Hill: New York, NY, USA, 2010.

20. Griffiths, P.; Renz, A.; Hughes, J.; Rafferty, A. Impact of organisation and management factors on infection control in hospitals: A scoping review. J. Hosp. Infect. 2009, 74, 1-14. [CrossRef] [PubMed]

21. Branningan, E.T.; Murray, E.; Holmes, A. Where does infection control fit into a hospital management structure? J. Hosp. Infect. 2009, 73, 392-396. [CrossRef] [PubMed]

22. Larson, E. Monitoring hand hygiene: Meaningless, harmful, or helpful? Am. J. Infect. Control 2013, 41, S42-S45. [CrossRef] [PubMed]

23. De Wandel, D.; Maes, L.; Labeau, S.; Vereecken, C.; Blot, S. Behavioral determinants of hand hygiene compliance in intensive care units. Am. J. Crit. Care 2010, 19, 230-239. [CrossRef] [PubMed]

24. Huis, A.; Achterberg, T.; Bruin, M.; Grol, R.; Schoonhoven, L.; Hulscher, M. A systematic review of hand hygiene improvement strategies: A behavioural approach. Implement. Sci. 2012. [CrossRef] [PubMed]

25. Pittet, D.; Hugonnet, S.; Mourouga, P.; Sauvan, V.; Touveneau, S.; Perneger, T.V. Effectiveness of hospital-wide programmes to improve compliance with hand hygiene. Lancet 2000, 356, 1307-1312. [CrossRef]

26. Pittet, D.; Simon, A.; Hugonnet, S.; Pessoa-Silva, C.L.; Sauvan, V.; Perneger, T.V. Hand hygiene among physicians: Performance, beliefs, and perceptions. Ann. Intern. Med. 2004, 141, 1-8. [CrossRef] [PubMed] 
27. Schweizer, M.L.; Reisinger, H.S.; Ohl, M.; Formanek, M.B.; Blevins, A.; Ward, M.A.; Perencevich, E.N. Searching for an optimal hand hygiene bundle: A meta-analysis. Clin. Infect. Dis. 2014, 58, 248-259. [CrossRef] [PubMed]

28. Ellingson, K.; Haas, J.P.; Aiello, A.E.; Kusek, L.; Maragakis, L.L.; Olmsted, R.N.; Perencevich, E.; Polgreen, P.M.; Schweizer, M.L.; Trexler, P.; et al. Strategies to prevent healthcare-associated infections through hand hygiene. Infect. Control. Hosp. Epidemiol. 2014, 35, 937-960. [CrossRef] [PubMed]

29. Harbarth, S. What can we learn from each other in infection control? Experience in Europe compared with the USA. J. Hosp. Infect. 2013, 83, 173-184. [CrossRef] [PubMed]

30. Körner, M.; Wirtz, M.A.; Bengel, J.; Göritz, A.S. Relationship of culture, teamwork and job satisfaction in interprofessional teams. BMC Health Serv. Res. 2015, 15, 245. [CrossRef] [PubMed]

31. Borg, M.A.; Benbachir, M.; Cookson, D.; Redjeb, S.B.; Elnasser, Z.; Rasslan, O.; Gür, D.; Daoud, Z.; Bagatzouni, D.P. Health care worker perceptions of hand hygiene practices and obstacles in a developing region. Am. J. Intect. Control. 2009, 37, 855-857. [CrossRef] [PubMed]

(C) 2017 by the authors. Licensee MDPI, Basel, Switzerland. This article is an open access article distributed under the terms and conditions of the Creative Commons Attribution (CC BY) license (http:/ / creativecommons.org/licenses/by/4.0/). 